\title{
Comparison between central and ambulatory blood pressure measurements in early detection of end organ damage: a single-center prospective non-randomized controlled trial
}

\author{
Doaa A. Fouad, Hosam Hassan Al Araby, Mohammad Ashraf and Ahmed El-Sherif El-Kousy * (D)
}

\begin{abstract}
Background: Both ambulatory blood pressure (AMBP) and non-invasive central blood pressure (NCBP) monitoring could be used as predictors for early detection of hypertensive end organ damage (EOD). However, the comparison between these two methods needs more clarification. Our cross-sectional study included 100 hypertensive patients with a mean age of $47.52 \pm 8.35$ years on regular antihypertensive treatment for $\geq 1$ year ( 50 controlled, 50 uncontrolled). We compared associations, sensitivity, and specificity of EOD parameters with office, AMBP, and NCBP measurements. We measured left ventricular mass index (LVMI), carotid intimal medial thickness (CIMT), ankle-brachial index (ABI), serum creatinine, glomerular filtration rate (GFR), and pulse wave velocity (PW).

Results: We found a significant relation between SBP of NCBP, AMBP and LVMI, and CIMT, PWV, and GFR respectively $(P<0.05)$ while office SBP showed no significant relation. Systolic AMBP showed a high sensitivity to ABI $(98 \%)$ and CIMT (92\%) while systolic NCBP had 92\% specificity and DBP showed 90\% sensitivity for ABI.

Conclusion: AMBP and NCBP show a significant relation to LVMI, CIMT, PWW, and GFR with little superiority of central BP while office BP does not. Systolic ABPM has high sensitivity to ABI and CIMT and systolic NCBP has a high sensitivity and specificity to $A B I$.
\end{abstract}

\section{Background}

Reliability of brachial blood pressure (BP) measurement in the physician's office has its own limitations, while out-of-office BP measurement, using either home BP monitoring or ambulatory BP monitoring (ABPM) techniques, is devoid of such limitations and is gaining importance in the management of hypertension.

It is now generally accepted that ABPM is an important adjunct to conventional office BP measurement, and ABPM became the "gold standard" for screening, diagnosis, and management of hypertension against the important limitations of office BP which have led to the increasingly frequent suggestion that ABPM [1]. Among the numerous

\footnotetext{
* Correspondence: Ahmedelkousy1988@gmail.com

Department of Cardiology, Faculty of Medicine, Assiut University Hospital, Assiut, Egypt
}

benefits of ABPM, the avoidance of potential BP measurement errors such as observer bias, terminal digit preference, and provision of more comprehensive information on BP behavior is possible with office or home BP. Ambulatory blood pressure monitors overcome this problem by obtaining multiple readings over the 24-h period and capturing the blood pressure variability [2].

Current non-invasive strategies for evaluating central aortic $\mathrm{BP}$ require recording of a blood vessel weight wave utilizing the MOBIL-O-GRAPH BP device which utilizes brachial $\mathrm{BP}$ waves for a non-invasive estimation of central BP [3]. When brachial artery blood pressure was used to stratify blood pressure measurements, a considerable overlap in aortic systolic pressure was observed, such that over $70 \%$ of individuals were categorized as having "high-normal" brachial systolic pressure based on Joint European Cardiology and Hypertension Society guidelines [4], and 
the authors postulated that we may be treating some patients with relatively low central pressures and not treating individuals with elevated central pressures, because they have brachial systolic pressures under current treatment thresholds. McEniery et al. [5] suggested that NICBP will have important clinical implications if central pressure turns out to be a better predictor of cardiovascular risk, because it suggests that. The Dicomano Study in Italy [6] and a Taiwanese study [7] also observed a stronger association between cardiovascular events and central, rather than brachial pressure. The heart, kidneys, and major arteries supplying the brain are exposed to aortic rather than brachial pressure. Therefore, there is a strong rationale to believe that cardiovascular events may ultimately be more closely related to central rather than brachial pressure. Evidence published over the last 12 years is concerning the relationship between central pressures [8].

\section{Methods}

The study group included 100 hypertensive patients recruited from the hypertension clinic in Assiut University Hospital, during the period from June 2016 to July 2017. Patients were divided into two groups, either controlled or uncontrolled office BP according to the European Society of Cardiology (ESC) guidelines 2013 ( $\geq 140 \mathrm{mmHg}$ systolic BP (SBP) and/or $\geq 90 \mathrm{mmHg}$ diastolic BP (DBP).

A detailed history was obtained, and complete clinical examination was performed including patients' weight and height to calculate body mass index (BMI).

Office pressure blood pressure measurement was done according to ESC 2013; we measured the systolic and diastolic blood pressure and compared the results with those of ABPM and NICBP.

For measurements of ABPM, we used NICE recommendations to ensure that at least two measurements per hour are taken during the person's usual waking hours. We used the average value of at least 14 measurements taken during the person's usual waking hours to confirm a diagnosis of hypertension. The device was programmed to obtain $\mathrm{BP}$ readings at 30-min interval during the day $(08: 00-22: 00 \mathrm{~h})$ and at 60 -min intervals during the night (22:00-08:00 h) [9]. We measured systolic and diastolic blood pressure and compared the results with those of office BP and NICBP.

Blood pressure varies over $24 \mathrm{~h}$ with a number of wellrecognized patterns. Dippers are individuals characterized by at least a $10 \%$ decline in nocturnal BP compared to their awake BP [10]. Most of the patients are dippers. Non-dippers are individuals having blunted or absent blood pressures which decline during sleep [11]. Approximately $10-30 \%$ of patients are "non-dippers," and in our study, non-dippers represent $34 \%$ of our patients.

We obtained the central blood pressure curve of our patients in a quiet, temperature-controlled examination room at the hypertension clinic. Three measurements were taken with a 2-min break between them by using Mobilograph device. The procedure was performed with the patient in a supine position and using an adequately sized cuff (the Mobil-O-Graph 24h PWA ABPM device (IEM, Stolberg, Germany) [12, 13]).

We measured systolic and diastolic blood pressures and compared them with the measurements of both office and ABPM.

We measured pulse wave velocity $(\mathrm{m} / \mathrm{s})$ (PWV) by Mobilograph and compared the result and age to detect the degree of arterial thickness related to hypertension. The slower the pulse wave velocity is, the better the heart health is. However, normal pulse wave velocity values vary according to age. We measured also the mean arterial pressure (MAP) and augmentation index (AI).

Blood samples were collected to measure serum creatinine and to exclude patients with a glomerular filtration rate of $<30 \mathrm{ml} / \mathrm{min} / 1.73 \mathrm{~m}^{2}$. The measurement of GFR was obtained by the Cockcroft-Gault formula study equation.

ECG was used to measure the left ventricular hypertrophy (LVH) using "Sokolow-Lyon $\geq 38 \mathrm{~mm}$ [14]. Echocardiography using Phillips IE33 ultrasound system was performed to all patients in addition to controls. Images were obtained from the short-axis view and longitudinal parasternal 4-chamber, 2-chamber, and 5-chamber slices. LV mass (LVM) and LVMI were calculate using LVMI $=$ LV mass $/$ BSA calculated by the Mosteller formula [15]. Ejection fraction (EF \%) was calculated using Simpson's method [16].

Carotid intimal medial thickness (CIMT) was measured with Doppler ultrasound (US) on the carotid artery to detect increased thickness related to hypertension. The intima-media complex can easily be distinguished from the surrounding tissue in US images, and the distinct borders allow for manual as well as automatic measurements of the CIMT. Damage is defined as the presence of CIMT $>0.9 \mathrm{~mm}$ or plaque [17].

ABI was calculated by measuring the systolic blood pressure from both brachial arteries and from both the dorsalis pedis and posterior tibial arteries at rest in the supine position. The systolic pressures were recorded with a handheld 5- or $10-\mathrm{mHz}$ Doppler instrument [18, 19]. Normal ABI ranges from 1.0 to 1.4; values above 1.4 suggest a non-compressible calcified vessel. However, a value below 0.9 is considered diagnostic of peripheral arterial disease (PAD).

\section{Statistical analysis}

The data were tested for normality using the Anderson-Darling test and for homogeneity variances prior to the further statistical analysis. Categorical variables 
were described by the number and percent $(N, \%)$, where continuous variables are described by mean and standard deviation (mean, SD). The chi-square test and Fisher exact test were used to compare categorical variables where comparisons between continuous variables were done by $t$ test and independent samples $t$ test ANOVA. A two-tailed $p<0.05$ was considered statistically significant. We used the Pearson and Spearman correlation to determine the association between variables. All analyses were performed with the IBM SPSS 20.0 software. The receiver operating characteristic (ROC) curve was done for the most powerful predictors for determination of cutoff point to be a risk factor for end organ damage. Post hoc tests are run to confirm where the differences occurred between groups; they should only be run when you have a shown an overall statistically significant difference in group means (i.e., a statistically significant one-way ANOVA result).

\section{Results}

The demographic and clinical characteristics of the study population are presented in Tables 1, 2, 3, 4 and 5, (Figs. 1, 2, 3 and 4).

\section{Discussion}

In our study, we found that $24 \mathrm{~h} \mathrm{ABPM}$ and non-invasive central BP monitoring are good predictable measures for early detection of hypertensive end organ damage.

In accordance with our results, Hansen et al. compare between $24 \mathrm{~h} \mathrm{ABPM}$ and office BP. ABPM and office BP were entered in the same multivariate models, only the ABPM was a significant predictor of all-cause mortality and cardiovascular mortality; however, the relative risks of cardiovascular mortality were lower for office blood pressure, and office blood pressure did not predict allcause mortality [20]. Wang et al. showed that central BP is more valuable than other blood pressure variables in predicting cardiovascular mortality [7].

Table 1 Characteristics of the controlled versus uncontrolled groups with office blood pressure measurement

\begin{tabular}{|c|c|c|c|c|}
\hline Variable & Controlled, $N=50$ & Uncontrolled, $N=50$ & $P$ & All, $N=100$ \\
\hline Male & $12(24 \%)$ & 15 (30\%) & \multirow[t]{2}{*}{0.499} & $27(27 \%)$ \\
\hline Female & $38(76 \%)$ & 35 (70\%) & & 73 (73\%) \\
\hline Age & $48.1 \pm 7.75$ & $46.94 \pm 8.96$ & 0.490 & $47.52 \pm 8.35$ \\
\hline BMI & $32.7 \pm 5.6$ & $31 \pm 5.22$ & 0.119 & $31.85 \pm 5.45$ \\
\hline Smoking & $12(24 \%)$ & $13(26 \%)$ & 0.817 & $25(25 \%)$ \\
\hline Duration of HTN & $6.78 \pm 4.47$ & $6.1 \pm 3.73$ & 0.411 & $6.44 \pm 4.11$ \\
\hline F. history & $28(56 \%)$ & 27 (54\%) & 0.841 & 55 (55\%) \\
\hline Office systolic & $135.12 \pm 19.45$ & $143.56 \pm 29.4$ & 0.087 & $138.58 \pm 24.25$ \\
\hline Office diastolic & $88.53 \pm 16.65$ & $85.37 \pm 15.04$ & 0.341 & $87.33 \pm 16.05$ \\
\hline ABPM systolic & $125.15 \pm 17.93$ & $128.96 \pm 25.9$ & 0.395 & $126.05 \pm 20.42$ \\
\hline ABPM diastolic & $87.63 \pm 18.52$ & $86.04 \pm 12.47$ & 0.616 & $86.84 \pm 15.99$ \\
\hline \multicolumn{5}{|l|}{ Night } \\
\hline Dipper & $36(72 \%)$ & $30(60 \%)$ & \multirow[t]{2}{*}{0.205} & $66(66 \%)$ \\
\hline Not dipper & $14(28 \%)$ & $20(40 \%)$ & & $34(34 \%)$ \\
\hline Central systolic & $126.07 \pm 19.41$ & $130.63 \pm 27.61$ & 0.348 & $127.44 \pm 22.14$ \\
\hline Central diastolic & $89.49 \pm 17.93$ & $88.77 \pm 13.89$ & 0.831 & $89.21 \pm 16.40$ \\
\hline PWV & $7.25 \pm 1.09$ & $7.8 \pm 1.33$ & $0.024^{*}$ & $7.52 \pm 1.24$ \\
\hline Augmentation index & $24.3 \pm 9.71$ & $25.84 \pm 11.75$ & 0.477 & $25.07 \pm 10.75$ \\
\hline MAP & $102.42 \pm 16.27$ & $98.88 \pm 14.53$ & 0.254 & $100.65 \pm 15.45$ \\
\hline $\mathrm{Cr}$ & $0.8 \pm 0.31$ & $1.04 \pm 0.34$ & $0.000^{* *}$ & $0.92 \pm 0.35$ \\
\hline GFR & $118.04 \pm 48.29$ & $94.88 \pm 51.17$ & $0.022^{*}$ & $106.46 \pm 50.85$ \\
\hline LVMI & $0.92 \pm 0.12$ & $0.95 \pm 0.13$ & 0.311 & $0.93 \pm 0.13$ \\
\hline $\mathrm{EF}$ & $59.34 \% \pm 5.69 \%$ & $59.12 \% \pm 5.83 \%$ & 0.849 & $59.23 \% \pm 5.73 \%$ \\
\hline CIMT & $0.7 \pm 0.12$ & $0.77 \pm 0.14$ & $0.008^{* *}$ & $0.74 \pm 0.13$ \\
\hline$A B \mid$ & $0.91 \pm 0.2$ & $0.95 \pm 0.27$ & 0.322 & $0.93 \pm 0.24$ \\
\hline
\end{tabular}

BMI body mass index, HTN hypertension, ABPM ambulatory blood pressure monitoring, $P W V$ pulse wave velocity, MAP mean arterial pressure, $C r$ creatinine, GFR glomerular filtration ratio, $L V M I$ left ventricular mass index, $E F$ ejection fraction, $C I M T$ carotid intimal thickness, $A B I$ ankle brachial index

* Statistically significant difference $(p<0.05),{ }^{* *}$ highly statistically significant difference $(p<0.01)$ 
Table 2 Blood pressure variability

\begin{tabular}{|c|c|c|c|}
\hline & ABPM SBP "controlled" & Central SBP "controlled" & $P$ \\
\hline SBP & $57(57 \%)$ & 70 (70\%) & 0.056 \\
\hline DBP & $56(56 \%)$ & $61(61 \%)$ & 0.473 \\
\hline Mean BP & $57(57 \%)$ & $67(67 \%)$ & 0.419 \\
\hline
\end{tabular}

After the analysis of our data, we found that all tools of BP measurements (Office -ABPM - Central) are correlated significantly with ECG changes (LVH or LBBB). ABPM SBP and DBP parameters are significantly correlated with ECG changes caused by hypertension. Central SBP, DBP, and PWV parameters are significantly correlated with ECG changes caused by hypertension.
We found that $24 \mathrm{~h}$ APBM and central BP are strong predictors for increasing in LVM as assessed by echocardiography. de Luca et al. showed the superiority of central SBP over brachial SBP as a major determinant of LVM regression which has recently been shown in 52 hypertensive patients treated with low-dose perindopril/indapamide and atenolol [21].

Central BP is more closely correlated with widely accepted surrogate measures of cardiovascular risk such as LVMI; a closer association of central pressure with LVMI was also found in the population-based Strong Heart Study [22] in which central systolic BP was more strongly associated with LVH determined by echocardiography. ABPM SBP and DBP parameters are significantly correlated with LVMI changes caused by hypertension. Central SBP and PWV parameters are significantly correlated with LVMI changes caused by hypertension.

Table 3 Relation between SBP measured by different tools monitoring and early hypertensive end organ damage

\begin{tabular}{|c|c|c|c|c|c|c|}
\hline & \multicolumn{2}{|l|}{ ABPM } & \multirow[t]{3}{*}{$P$ value } & \multicolumn{2}{|l|}{ Central } & \multirow[t]{3}{*}{$P$ value } \\
\hline & Controlled & Not controlled & & Controlled & Not controlled & \\
\hline & No. (\%) & No. (\%) & & No. (\%) & No. (\%) & \\
\hline \multicolumn{7}{|l|}{ ECG } \\
\hline Normal & $48(96 \%)$ & $13(26 \%)$ & $0.000^{* *}$ & 49 (90.7\%) & $12(26.1 \%)$ & $0.000^{* *}$ \\
\hline $\mathrm{LVH}$ & $2(4 \%)$ & $34(68 \%)$ & & $5(9.3 \%)$ & 31 (67.4\%) & \\
\hline LBBB & $0(0 \%)$ & $3(6 \%)$ & & $0(0 \%)$ & $3(6.5 \%)$ & \\
\hline \multicolumn{7}{|l|}{ LVMI } \\
\hline Normal & 47 (94\%) & 37 (74\%) & $0.006^{* *}$ & 52 (96.3\%) & 32 (69.6\%) & $0.000^{* *}$ \\
\hline Abnormal & $3(6 \%)$ & $13(26 \%)$ & & $2(3.7 \%)$ & $14(30.4 \%)$ & \\
\hline \multicolumn{7}{|l|}{ CIMT } \\
\hline Normal & 47 (94\%) & 37 (74\%) & $0.006^{* *}$ & $51(94.4 \%)$ & $33(71.7 \%)$ & $0.002^{* *}$ \\
\hline Abnormal & $3(6 \%)$ & $13(26 \%)$ & & $3(5.6 \%)$ & $13(28.3 \%)$ & \\
\hline \multicolumn{7}{|l|}{ PWV } \\
\hline Normal & $50(100 \%)$ & $43(86 \%)$ & $0.006^{* *}$ & $54(100 \%)$ & 39 (84.8\%) & $0.003^{* *}$ \\
\hline Abnormal & $0(0 \%)$ & $7(14 \%)$ & & $0(0 \%)$ & 7 (15. 2\%) & \\
\hline \multicolumn{7}{|l|}{$A B \mid$} \\
\hline Normal & 39 (78\%) & $21(42 \%)$ & $0.000^{* *}$ & 41 (75.9\%) & 19 (41.3\%) & $0.000^{* *}$ \\
\hline Abnormal & $11(22 \%)$ & 29 (58\%) & & $13(24.1 \%)$ & 27 (58.7\%) & \\
\hline \multicolumn{7}{|l|}{ Creatinine } \\
\hline Normal & 47 (94\%) & $30(60 \%)$ & $0.000^{* *}$ & 52 (96.3\%) & 25 (54.3\%) & $0.000^{* *}$ \\
\hline Abnormal & $3(6 \%)$ & $20(40 \%)$ & & $2(3.7 \%)$ & $21(45.7 \%)$ & \\
\hline \multicolumn{7}{|l|}{ GFR } \\
\hline Normal & 47 (94\%) & 36 (72\%) & $0.003^{* *}$ & $50(92.6 \%)$ & $33(71.7 \%)$ & $0.006^{* *}$ \\
\hline Abnormal & $3(6 \%)$ & $14(28 \%)$ & & $4(7.4 \%)$ & $13(28.3 \%)$ & \\
\hline
\end{tabular}

Chi-square test

*Statistically significant difference $(p<0.05)$

**Highly statistically significant difference $(p<0.01)$

HTN hypertension, ABPM ambulatory blood pressure monitoring, PWV pulse wave velocity, Cr creatinine, GFR glomerular filtration ratio, LVMI left ventricular mass index, CIMT carotid intimal thickness, $A B I$ ankle-brachial index 
Table 4 The correlation between each blood pressure monitoring and hypertensive end organ damage parameters

\begin{tabular}{|c|c|c|c|c|c|c|c|c|}
\hline & & LVMI & CIMT & PWV & $A B \mid$ & $\mathrm{Cr}$ & GFR & ECG \\
\hline \multirow[t]{2}{*}{ ABPM SBP } & $R$ & 0.326 & 0.385 & 0.336 & 0.439 & 0.473 & -0.265 & 0.793 \\
\hline & $P$ & $<0.001^{* *}$ & $<0.001^{* *}$ & $<0.001^{* *}$ & $<0.001^{* *}$ & $<0.001^{* *}$ & $0.008^{*}$ & $<0.001^{* *}$ \\
\hline \multirow[t]{2}{*}{ ABPM DBP } & $R$ & 0.286 & 0.317 & 0.214 & 0.418 & 0.325 & -0.181 & 0.656 \\
\hline & $P$ & $0.004^{* *}$ & $<0.001^{* *}$ & 0.032 & $<0.001^{* *}$ & $<0.001^{* *}$ & 0.072 & $<0.001^{* *}$ \\
\hline \multirow[t]{2}{*}{ Central SBP } & $R$ & 0.347 & 0.330 & 0.369 & 0.437 & 0.439 & -0.254 & 0.720 \\
\hline & P & $<0.001^{* *}$ & $<0.001^{* *}$ & $<0.001^{* *}$ & $<0.001^{* *}$ & $<0.001^{* *}$ & $0.011^{*}$ & $<0.001^{* *}$ \\
\hline \multirow[t]{2}{*}{ Central DBP } & $R$ & 0.111 & 0.118 & 0.209 & 0.156 & 0.133 & 0.046 & 0.506 \\
\hline & $P$ & 0.271 & 0.243 & $0.037^{*}$ & 0.120 & 0.186 & 0.651 & $<0.001^{* *}$ \\
\hline
\end{tabular}

$R$ value is the correlation coefficient $r$ measures the strength and direction of a linear relationship between two variables on a scatterplot. The value of $r$ is always between +1 and -1

$S B P$ systolic blood pressure, DBP diastolic blood pressure, HTN hypertension, $A B P M$ ambulatory blood pressure monitoring, $P W V$ pulse wave velocity, $C r$ creatinine, GFR glomerular filtration ratio, $L V M I$ left ventricular mass index, CIMT carotid intimal thickness, $A B I$ ankle-brachial index

*Statistically significant difference $(p<0.05)$

**Highly statistically significant difference $(p<0.01)$

Table 5 Logistic regression models for hypertensive end organ damage

\begin{tabular}{|c|c|c|c|c|c|c|c|c|}
\hline & \multicolumn{4}{|l|}{ ECG } & \multicolumn{4}{|l|}{ LVMI } \\
\hline & Odds ratio & \multicolumn{2}{|c|}{$\begin{array}{l}\text { Confidence } \\
\text { interval }\end{array}$} & $P$ value & Odds ratio & $\begin{array}{l}\text { Confidence } \\
\text { interval }\end{array}$ & \multicolumn{2}{|l|}{$P$ value } \\
\hline $\begin{array}{l}\text { AMBP SBP } \\
\text { (uncontrolled/controlled) }\end{array}$ & 0.081 & \multicolumn{2}{|c|}{$0.029-0.224$} & $0.000^{* *}$ & 0.200 & $0.065-0.617$ & \multicolumn{2}{|l|}{$0.005^{* *}$} \\
\hline $\begin{array}{l}\text { AMBP MAP } \\
\text { (uncontrolled/controlled) }\end{array}$ & 0.101 & \multicolumn{2}{|c|}{$0.030-0.334$} & $0.000^{* *}$ & 0.167 & $0.053-0.529$ & \multicolumn{2}{|l|}{$0.002^{* *}$} \\
\hline $\begin{array}{l}\text { Central SBP } \\
\text { (uncontrolled/controlled) }\end{array}$ & 0.670 & \multicolumn{2}{|c|}{$0.271-1.656$} & 0.386 & 0.376 & $0.124-1.143$ & \multicolumn{2}{|l|}{0.085} \\
\hline \multirow{3}{*}{$\begin{array}{l}\text { Central MAP } \\
\text { (uncontrolled/controlled) }\end{array}$} & 0.286 & \multicolumn{2}{|c|}{$0.117-0.697$} & $0.006^{* *}$ & 0.355 & $0.119-1.060$ & \multicolumn{2}{|l|}{0.063} \\
\hline & CIMT & & & & PWV & & & \\
\hline & Odds ratio & \multicolumn{2}{|c|}{$\begin{array}{l}\text { Confidence } \\
\text { interval }\end{array}$} & $P$ value & Odds ratio & $\begin{array}{l}\text { Confidence } \\
\text { interval }\end{array}$ & \multicolumn{2}{|l|}{$P$ value } \\
\hline $\begin{array}{l}\text { AMBP SBP } \\
\text { (uncontrolled/controlled) }\end{array}$ & 0.514 & \multicolumn{2}{|c|}{$0.172-1.538$} & 0.234 & 0.061 & $0.007-0.535$ & \multicolumn{2}{|l|}{$0.012^{*}$} \\
\hline $\begin{array}{l}\text { AMBP MAP } \\
\text { (uncontrolled/controlled) }\end{array}$ & 0.706 & \multicolumn{2}{|c|}{$0.201-2.478$} & 0.587 & 0.298 & $0.061-1.458$ & \multicolumn{2}{|l|}{0.135} \\
\hline $\begin{array}{l}\text { Central SBP } \\
\text { (uncontrolled/controlled) }\end{array}$ & 0.059 & \multicolumn{2}{|c|}{$0.006-0.524$} & $0.014^{*}$ & 0.065 & $0.008-0.564$ & \multicolumn{2}{|l|}{$0.010^{*}$} \\
\hline $\begin{array}{l}\text { Central MAP } \\
\text { (uncontrolled/controlled) }\end{array}$ & 0.355 & \multicolumn{2}{|c|}{$0.119-1.060$} & 0.063 & 0.075 & $0.010-0.602$ & \multicolumn{2}{|l|}{$0.014^{*}$} \\
\hline$A B \mid$ & & \multicolumn{3}{|c|}{$\mathrm{Cr}$} & & \multicolumn{3}{|l|}{ GFR } \\
\hline Odds ratio & $\begin{array}{l}\text { Confidence } \\
\text { interval }\end{array}$ & $P$ value & Odds ratio & $\begin{array}{l}\text { Confidence } \\
\text { interval }\end{array}$ & $P$ value & Odds ratio & $\begin{array}{l}\text { Confidence } \\
\text { interval }\end{array}$ & $P$ value \\
\hline 0.144 & $0.056-0.371$ & $0.000^{* *}$ & 0.383 & $0.146-1.003$ & 0.051 & 0.487 & $0.171-1.388$ & 0.178 \\
\hline 0.206 & $0.071-0.598$ & $0.004^{* *}$ & 0.259 & $0.090-0.743$ & $0.012^{*}$ & 0.412 & $0.142-1.283$ & 0.126 \\
\hline 0.710 & $0.288-1.752$ & 0.457 & 1.350 & $0.445-4.098$ & 0.596 & 0.474 & $0.161-1.392$ & 0.174 \\
\hline 0.556 & $0.234-1.322$ & 0.184 & 2.192 & $0.832-5.778$ & 0.112 & 1.140 & $0.367-3.543$ & 0.820 \\
\hline
\end{tabular}

Logistic regression included the following independent variables: central SBP: uncontrolled = 1/controlled = 2; central MAP: abnormal = 1/normal = 2; ABPM SBP: uncontrolled $=1 /$ controlled $=2 ;$ ABPM MAP: uncontrolled $=1 /$ controlled $=2$. Values in italics represent significant $P$ value $<0.05$

$A B P M$ ambulatory blood pressure monitoring, PWV pulse wave velocity, Cr creatinine, GFR glomerular filtration ratio, LVMI left ventricular mass index, CIMT carotid intimal thickness, $A B I$ ankle-brachial index

*Statistically significant difference $(p<0.05)$

**Highly statistically significant difference $(p<0.01)$ 


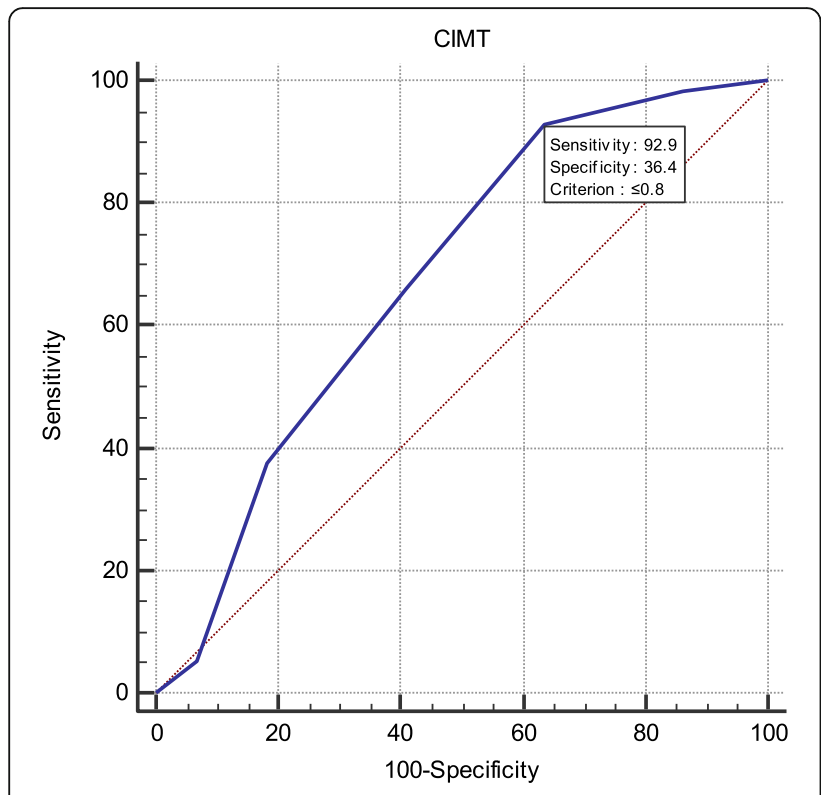

Fig. 1 High sensitivity of ABPM DBP with CIMT (92.9\%)

Central BP and 24 $\mathrm{h}$ ABPM are significantly related to the changes in CIMT which are caused by hypertension. Mancia et al. had found that the end organ damage was determined not only by the degree of the high BP level but also by the $24 \mathrm{~h}$ ABPM. In our study, we found that both ABPM and central BP are also good predictors for CIMT changes but office BP is not conclusive for hypertensive CIMT changes. ABPM SBP and DBP parameters are significantly correlated with CIMT changes caused by hypertension. Central SBP and PWV parameters are significantly correlated with CIMT changes caused by hypertension.



Fig. 2 High sensitivity of ABPM SBP with ABI (98.2\%)

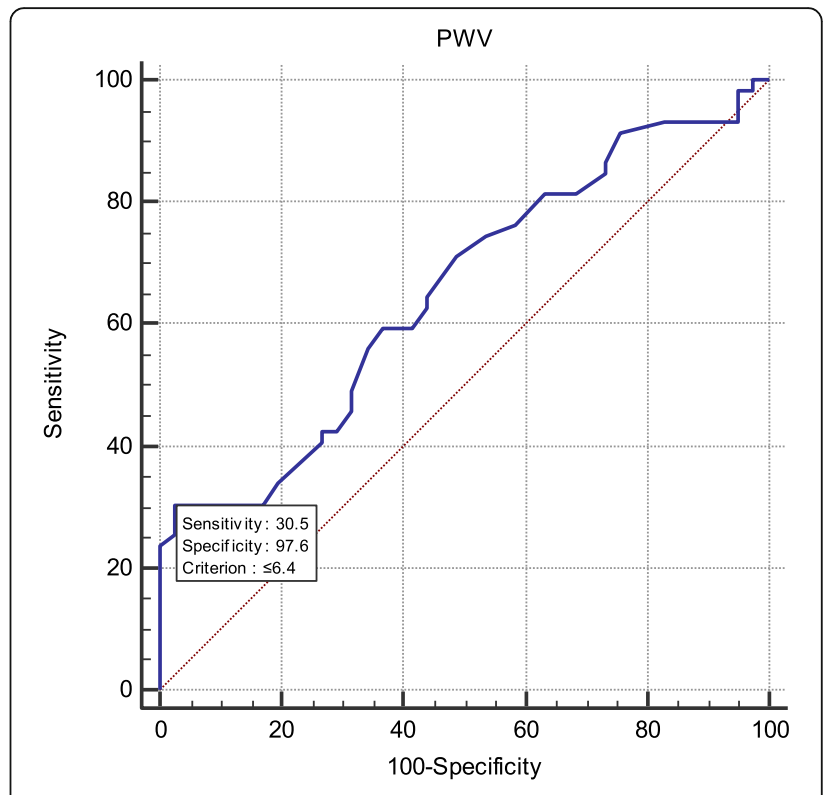

Fig. 3 High specificity of central SBP with PWV (97.6\%)

PWV is an important marker for cardiovascular changes, and in our study, we find that both ABPM and central BP are significantly related to PWV with some superiority to central BP. In accordance with our results, Spronck et al. stated that office and out-of-office BP are independent predictors of aortic PWV in hypertension.

Elevated BP values over the $24 \mathrm{~h}$ are associated with increased aortic stiffness, so ABPM is a good predictor [23]. ABPM SBP and DBP parameters are significantly correlated with PWV changes caused by hypertension.

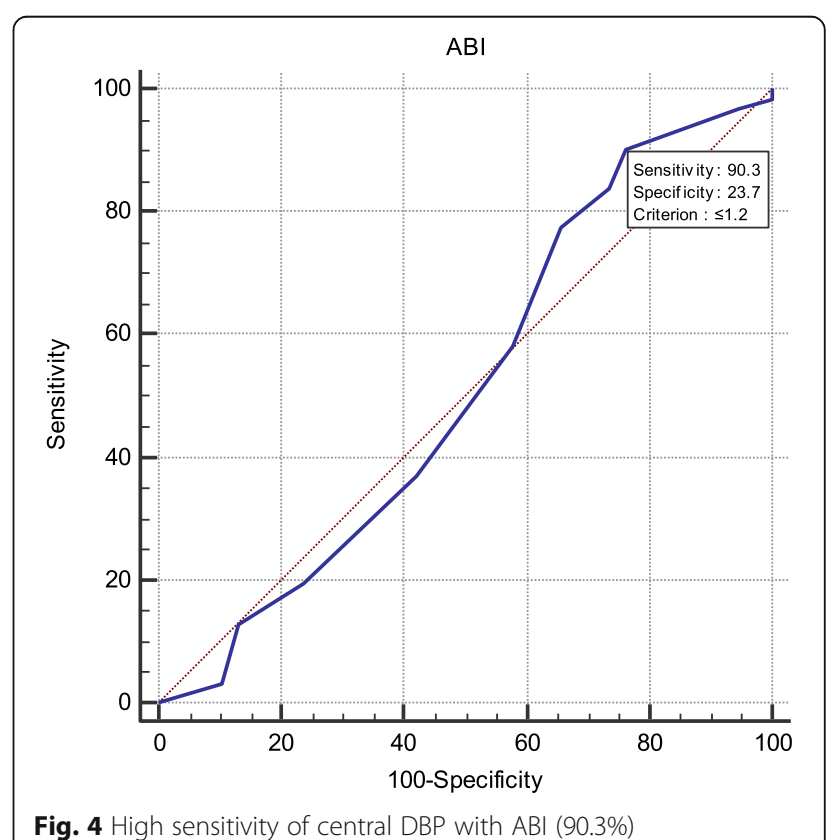


Central SBP parameter is significantly correlated with PWV changes caused by hypertension.

In our study, we found that both $24 \mathrm{~h} \mathrm{ABPM}$ and central $\mathrm{BP}$ are more predictable than office $\mathrm{BP}$; however, Wittke et al. showed that the variability of systolic blood pressure over time derived from ABPM is associated with the ankle-brachial index [24]. ABPM SBP and DBP parameters are significantly correlated with $A B I$ changes caused by hypertension. Central SBP, DBP, and PWV parameters are significantly correlated with $\mathrm{ABI}$ changes caused by hypertension.

Both ABPM and Central BP are correlated with changes in $\mathrm{Cr}$ level and GFR caused by hypertension in our study. However, this point is controversial with many studies, such as the Framingham Heart Study, which failed to identify an association between central BP and renal function [25] while Karras et al. [26] demonstrated that central hemodynamic and arterial stiffness parameters are associated with renal impairment. ABPM SBP and DBP parameters are significantly correlated with $\mathrm{Cr}$ level changes caused by hypertension. Central SBP, DBP, and PWV parameters are significantly correlated with $\mathrm{Cr}$ level changes caused by hypertension.

\section{Conclusion}

AMBP and NCBP show a significant relation to LVMI, CIMT, PWV, and GFR with little superiority of central BP while office BP does not. Systolic AMBP has high sensitivity to $\mathrm{ABI}$ and CIMT and systolic NCBP has a high sensitivity and specificity to $\mathrm{ABI}$.

\section{Abbreviations \\ $\mathrm{ABI}$ : Ankle-brachial index; ABPM: Ambulatory blood pressure monitoring: BP: Blood pressure; BPV: Blood pressure variability; CIMT: Carotid intimal medial thickness; Cr: Creatinine; CV: Cardiovascular; DBP: Diastolic BP; ECG: Electrocardiogram; ESC: European Society of Cardiology; GFR: Glomerular filtration ratio; IMT: Intimal medial thickness; LV: Left ventricular; LVH: Left ventricular hypertrophy; LVMl: Left ventricular mass index; PWV: Pulse wave velocity; SBP: Systolic blood pressure}

\section{Acknowledgements}

First of all, all gratitude is due to Allah the almighty that guided and aided me in bringing this thesis to light which would have never been crowned by success without the blessing of Allah to whom my faithful loyalty will remain however beyond any compromises. I would like to express my thanks to my professors, colleagues, and patients and their relatives for their great help.

My great appreciation and praise go to my family especially my father, my mother, and my wife for their support throughout the whole duration of the study.

\section{Study limitations}

1. The difference in time of measuring ABPM was done over $24 \mathrm{~h}$ while central blood pressure monitoring during only $30 \mathrm{~min}$

2. Investigations were done over a period of several days which was an obstacle for some patients to continue in the study. These patients had to be excluded

3. Unawareness of the serious complications of hypertension for many patients

4. The small number of patient population

\section{Authors' contributions}

MA carried out the practical part of the research with AS, then $\mathrm{HH}$ and DF made the plan of the work and check every single detail in the research. All authors have read and approved the manuscript.

Funding

No funding was received for this study.

\section{Availability of data and materials}

The data and materials are available in our cardiology department.

\section{Ethics approval and consent to participate}

Prior to subject recruitment, the study protocol was reviewed and approved by the research ethics committee of the Faculty of Medicine Assiut

University. Oral and written consents were obtained from all the participants in the study.

\section{Consent for publications}

All participants in the study approved the publication.

\section{Competing interest}

No funding was received for this study; all materials were taken from the Department of Cardiology, Assiut Hospital. The authors declare that they have no competing interests.

Received: 19 June 2019 Accepted: 24 July 2019

Published online: 10 September 2019

\section{References}

1. O'brien E, Parati G, Stergiou G, Asmar R, Beilin L, Bilo G et al (2013) European Society of Hypertension position paper on ambulatory blood pressure monitoring. J Hypertens 31(9):1731-1768

2. Anwar YA, White WB. Ambulatory monitoring of blood pressure. Blood pressure monitoring in cardiovascular medicine and therapeutics: Springer; 2001. p. 57-75.

3. Lim SS, Vos T, Flaxman AD, Danaei G, Shibuya K, Adair-Rohani H et al (2012) A comparative risk assessment of burden of disease and injury attributable to 67 risk factors and risk factor clusters in 21 regions, 1990-2010: a systematic analysis for the Global Burden of Disease Study 2010. The lancet. 380(9859):2224-2260

4. Mancia G, Laurent S, Agabiti-Rosei E, Ambrosioni E, Burnier M, Caulfield MJ et al (2009) Reappraisal of European guidelines on hypertension management: a European Society of Hypertension Task Force document. Blood pressure. 18(6):308-347

5. McEniery CM, Cockcroft JR, Roman MJ, Franklin SS, Wilkinson IB (2014) Central blood pressure: current evidence and clinical importance. European heart journal. 35(26): 1719-1725

6. Pini R, Cavallini MC, Palmieri V, Marchionni N, Di Bari M, Devereux RB et al (2008) Central but not brachial blood pressure predicts cardiovascular events in an unselected geriatric population: the ICARe Dicomano Study. J Am Coll Cardiol 51(25):2432-2439

7. Wang K-L, Cheng H-M, Chuang S-Y, Spurgeon HA, Ting C-T, Lakatta EG et al (2009) Central or peripheral systolic or pulse pressure: which best relates to target-organs and future mortality. Journal of hypertension. 27(3):461

8. Laurent S, Boutouyrie P (2007) Arterial stiffness: a new surrogate end point for cardiovascular disease? J Nephrol 20:S45-S50

9. McCormack T, Krause T, O'Flynn N (2012) Management of hypertension in adults in primary care: NICE guideline. Br J Gen Pract. 62(596):163-164

10. Snyder F, Hobson JA, Morrison DF, Goldfrank F (1964) Changes in respiration, heart rate, and systolic blood pressure in human sleep. Journal of Applied Physiology. 19(3):417-422

11. Staessen JA, Thijs L, Fagard R, O'brien ET, Clement D, de Leeuw PW et al (1999) Predicting cardiovascular risk using conventional vs ambulatory blood pressure in older patients with systolic hypertension. Jama. 282(6):539-546

12. Jones CR, Taylor K, Chowienczyk P, Poston L, Shennan AH (2000) A validation of the Mobil O Graph (version 12) ambulatory blood pressure monitor. Blood pressure monitoring. 5(4):233-238

13. Franssen PM, Imholz BP (2010) Evaluation of the Mobil-O-Graph new generation ABPM device using the ESH criteria. Blood Press Monit 15(4):229-231 
14. Okin PM, Roman MJ, Devereux RB, Pickering TG, Borer JS, Kligfield P (1998) Time-voltage QRS area of the 12-lead electrocardiogram. Hypertension. 31(4):937-942

15. Mosteller RD. Simplified calculation of body surface area. N Engl J Med. 1987;317:1098.

16. Lang RM, Badano LP, Mor-Avi V, Afilalo J, Armstrong A, Ernande L et al (2015) Recommendations for cardiac chamber quantification by echocardiography in adults: an update from the American Society of Echocardiography and the European Association of Cardiovascular Imaging. European Heart Journal-Cardiovascular Imaging. 16(3):233-271

17. Pignoli P, Tremoli E, Poli A, Oreste P, Paoletti R (1986) Intimal plus medial thickness of the arterial wall: a direct measurement with ultrasound imaging. circulation. 74(6):1399-1406

18. WOCN CPWS. Ankle brachial index: quick reference guide for clinicians. J Wound Ostomy Continence Nurs 2012;39(2 Suppl):S21.

19. Kim E, Wattanakit K, Gornik HL (2012) Using the ankle-brachial index to diagnose peripheral artery disease and assess cardiovascular risk. Cleve Clin J Med 79(9):651-661

20. Hansen TW, Jeppesen J, Rasmussen S, Ibsen H, Torp-Pedersen C (2005) Ambulatory blood pressure and mortality. Hypertension. 45(4):499-504

21. de Luca N, Asmar RG, London GM (2004) O'rourke MF, Safar ME. Selective reduction of cardiac mass and central blood pressure on low-dose combination perindopril/indapamide in hypertensive subjects. J Hypertens 22(8):1623-1630

22. Roman MJ, Devereux RB, Kizer JR, Lee ET, Galloway JM, Ali T et al (2007) Central pressure more strongly relates to vascular disease and outcome than does brachial pressure. Hypertension. 50(1):197-203

23. Spronck B, Heusinkveld MH, Vanmolkot FH, Op't Roodt J, Hermeling E, Delhaas T et al (2015) Pressure-dependence of arterial stiffness: potentia clinical implications. J Hypertens 33(2):330-338

24. Wittke E, Fuchs SC, Fuchs FD, Moreira LB, Ferlin E, Cichelero FT et al (2010) Association between different measurements of blood pressure variability by $\mathrm{ABP}$ monitoring and ankle-brachial index. BMC cardiovascular disorders. 10(1):55

25. Upadhyay A, Hwang S-J, Mitchell GF, Vasan RS, Vita JA, Stantchev PI et al (2009) Arterial stiffness in mild-to-moderate CKD. Journal of the American Society of Nephrology. 20(9):2044-2053

26. Karras A, Haymann J-P, Bozec E, Metzger M, Jacquot C, Maruani G, Houillier P, Froissart M, Stengel B, Guardiola P (2012) Large artery stiffening and remodeling are independently associated with all-cause mortality and cardiovascular events in chronic kidney disease. Hypertension. 2012;60(6): $1451-7$

\section{Publisher's Note}

Springer Nature remains neutral with regard to jurisdictional claims in published maps and institutional affiliations.

\section{Submit your manuscript to a SpringerOpen ${ }^{\circ}$ journal and benefit from:}

- Convenient online submission

- Rigorous peer review

- Open access: articles freely available online

- High visibility within the field

- Retaining the copyright to your article

Submit your next manuscript at $\boldsymbol{\nabla}$ springeropen.com 